\title{
Comparison of Proximal Caries Detection in Primary Teeth between Laser Fluorescence and Bitewing Radiography: An in vivo Study
}

\author{
${ }^{1}$ Ratheesh Mepparambath, ${ }^{2}$ Sham S Bhat, ${ }^{3}$ Sundeep K Hegde, ${ }^{4}$ G Anjana, ${ }^{5} \mathrm{M}$ Sunil, ${ }^{6}$ Sherryl Mathew
}

\begin{abstract}
Background and objective: Proximal caries detection is of great importance because of the rapid rate of caries progression and the difficulty in determining the absence or presence of a lesion in primary dentition. Although, various methods for caries diagnosis offer good diagnostic performances, they provide varying sensitivities for detecting proximal carious lesions. The objective of this study was to compare, in vivo, the accuracy of DIAGNOdent and bitewing radiography at detecting proximal caries in primary teeth.
\end{abstract}

Materials and methods: One Hundred and one primary maxillary and mandibular molars without obvious cavities of children between the age group of 3 and 10 years were included. The teeth were first subjected to DIAGNOdent examination followed by bitewing radiography. The specificity and sensitivity of the systems were calculated.

Results: At the dentin caries (D3) level, the sensitivity of DIAGNOdent and bitewing radiography was $78.5 \%$; at the enamel caries (D1 and D2) level it was $39.12 \%$ and for the sound teeth (D0) it was found to be $76.52 \%$. A strong association was observed between the DIAGNOdent and the bitewing radiograph $(p<0.001)$.

Conclusion: The DIAGNOdent can be used as an alternative diagnostic method in detection of proximal caries in primary teeth. But when seen at the each caries level, the DIAGNOdent is more accurate at the D0 and D3 threshold.

Keywords: DIAGNOdent, Bitewing radiograph, Proximal caries detection, Primary teeth, Dentin caries, Enamel caries.

How to cite this article: Mepparambath R, Bhat SS, Hegde SK, Anjana G, Sunil M, Mathew S. Comparison of Proximal Caries Detection in Primary Teeth between Laser Fluorescence and Bitewing Radiography: An in vivo Study. Int J Clin Pediatr Dent 2014;7(3):163-167

Source of support: Nil

Conflict of interest: None

\footnotetext{
${ }^{1,6}$ Senior Lecturer, ${ }^{2,4}$ Professor and Head, ${ }^{3,5}$ Professor

1,4-6 Department of Pedodontics and Preventive Dentistry, Royal Dental College, Palakkad, Kerala, India

${ }^{2,3}$ Department of Pedodontics and Preventive Dentistry Yenepoya Dental College, Mangalore, Karnataka, India
}

Corresponding Author: Ratheesh Mepparambath, Senior Lecturer, Department of Pedodontics and Preventive Dentistry Royal Dental College, Palakkad, Kerala, India, Phone: 09446248678, e-mail:dr_ratheeshms@yahoo.co.in

\section{INTRODUCTION}

Among the different types of carious lesions, proximal caries is notorious for its rapid rate of progression and the difficulty in determining the presence of the lesion. ${ }^{1-3}$ It has been established by various authors that the radiographic techniques are superior over clinical examination in the detection of interproximal carious lesions. ${ }^{4-8}$

But, bitewing radiographs, which is the most common method used to diagnose proximal caries, exposes the patient to a relatively high dose of ionizing radiation. ${ }^{9}$ Alternative methods to detect proximal caries, like the DIAGNOdent, are expected to overcome the disadvantages of these conventional methods. ${ }^{10}$

Hibst and Paulus ${ }^{11}$ discovered that bacterial metabolites within caries produce fluorescence that can be enhanced by a laser light. Based on this, the DIAGNOdent (KaVo, Biberach, Germany), a portable laser diode based device was developed. ${ }^{12}$ DIAGNOdent's accuracy has been studied both in vitro and in vivo for occlusal caries in primary and permanent teeth. ${ }^{10,13-15}$ Several investigations indicate that DIAGNOdent could be applied for use on smooth surface caries and proximal caries of permanent teeth. ${ }^{10,16-18}$ The results of these studies show that DIAGNOdent is accurate and reproducible in caries detection. But, only a few studies have indicated its use on the proximal surfaces of primary teeth. ${ }^{10}$

Therefore, the aim of our study was to compare, in vivo, accuracy of DIAGNOdent and bitewing radiography at detecting proximal caries in primary teeth.

\section{MATERIALS AND METHODS}

The study was reviewed and approved by the Ethics Committee of Yenepoya University, Mangalore, India.

\section{Patient Selection}

One hundred and one deciduous maxillary and mandibular molars without obvious cavities were identified in children between the age group of 3 to 10 years who had reported to the Department of Pedodontics and Preventive Dentistry, Yenepoya Dental College and Hospital, Mangalore, India. Once the prospective patients were identified, the procedure and aims of the study were 
explained to them or their guardian and informed consent was obtained.

The following inclusion criteria were used to determine entry into the study: the included teeth must be deciduous maxillary or mandibular molars; the tooth must be intact or cavities if present should be less than $1 \mathrm{~mm}$ in diameter on the proximal surface. Teeth with frank cavitation or symptoms of pulpitis; presence of proximal restorations or hypoplastic pits were excluded from participation in the study.

\section{DIAGNOdent Examination}

As per the manufacturer's instructions, calibration of the DIAGNOdent (KaVo, Biberach, Germany) was performed with a ceramic standard provided by the company for every patient. Following the tooth selection, oral prophylaxis was performed and polishing of the teeth were done using rubber cup and pumice/water slurry. The preselected teeth were air dried using a three way syringe and the Probe A of the DIAGNOdent was used for the examination. The tip of the laser device was then placed perpendicular to the surface being examined, i.e. at the marginal ridge of the occlusal surface and at the buccal and lingual embrasures.

The DIAGNOdent device has two displays: one shows the moment reading and the other shows the peak reading. The moment reading indicates the real time

Table 1: Caries interpretation based on the criteria put forward by the manufacturer (KaVo, 2001)

\begin{tabular}{ll}
\hline Caries level & Interpretation \\
\hline Sound (D0) & $0-9$ \\
Enamel caries (D1-D2) & $10-17$ \\
Dentin caries (D3) & $18-99$ \\
\hline
\end{tabular}

Table 2: Radiographic interpretation based on criteria put forward by Pitts $(1984)^{33}$

\begin{tabular}{|c|c|c|}
\hline Score & Caries level & Criteria \\
\hline R0 & D0-Sound & No Radiolucency \\
\hline R1 & D1-Initial caries & $\begin{array}{l}\text { Zone of increased radiolucency, } \\
\text { confined to outer half of enamel }\end{array}$ \\
\hline $\mathrm{R} 2$ & D2-Enamel caries & $\begin{array}{l}\text { Zone of increased radiolucency } \\
\text { involving both inner and outer } \\
\text { halves of enamel layer, including } \\
\text { lesions extending up to but not } \\
\text { beyond the DEJ }\end{array}$ \\
\hline R3 & D3-Dentin caries & $\begin{array}{l}\text { Zone of increased radiolucency } \\
\text { penetrating the enamel and DEJ } \\
\text { and progressing into the dentin }\end{array}$ \\
\hline
\end{tabular}

Table 3: Total number of teeth examined

\begin{tabular}{llll}
\hline Teeth examined & First molar & Second molar & Total \\
\hline Maxillary teeth & 25 & 24 & 49 \\
Mandibular teeth & 26 & 26 & 52 \\
\hline Total & 51 & 50 & 101 \\
\hline
\end{tabular}

value that the probe tip measures during the scanning of the surface. The peak reading refers to the highest level scanned on the tooth surface.

The peak reading for each tooth was recorded. The readings were then interpreted according to the criteria put forward by the manufacturer (KaVo, 2001) (Table 1).

\section{Bitewing Radiography}

Once the DIAGNOdent recordings of the teeth were completed, the bitewing radiographs were taken under standardized conditions. A bitewing holder was used to hold the radiograph in position. If any defect such as overlapping of the teeth occurred, the radiographs were repeated.

The radiographs taken were interpreted as per the criteria put forward by Pitts $(1984)^{19}$ (Table 2).

The obtained results were statistically analyzed to obtain the sensitivity and specificity using the Chi-square test.

\section{RESULTS}

A total of 101 maxillary and mandibular primary molars without obvious cavities were identified in children between the age group of 3 and 10 years. The distribution of the teeth examined is illustrated as shown in Table 3.

Of the 101 teeth selected, the total surfaces examined were 169. Tooth surface without contact to the adjacent tooth was not examined. Table 4 illustrates the distribution of the teeth surfaces examined.

Of the 169 teeth surfaces examined, the DIAGNOdent interpretation showed 110 teeth surfaces to have no caries (sound), 34 surfaces as enamel caries and 25 surfaces as dentinal caries. Table 5 illustrates the DIAGNOdent interpretation.

Of the 169 teeth surfaces interpreted by radiographs, 132 teeth surfaces showed no radiolucency, 17 surfaces showed zone of radiolucency confined to the outer half of the enamel, 6 teeth surfaces showed zone of radiolucency involving both the inner and outer halves of the enamel

Table 4: Total number of teeth surfaces examined

\begin{tabular}{llll}
\hline Teeth examined & First molar & Second molar & Total \\
\hline Maxillary teeth & 38 & 42 & 79 \\
Mandibular teeth & 43 & 46 & 90 \\
\hline Total & 81 & 88 & 169 \\
\hline
\end{tabular}

Table 5: Caries distribution as per DIAGNOdent interpretation

\begin{tabular}{lll}
\hline Criteria & Caries level & No. of teeth \\
\hline Sound (0-9) & D0 & 110 \\
Enamel caries (10-17) & D1 + D2 & 34 \\
Dentin caries (18-99) & D3 & 25 \\
\hline Total & & 169 \\
\hline
\end{tabular}


Table 6: Caries distribution as per radiographic interpretation

\begin{tabular}{|c|c|c|c|}
\hline Score & Caries level & Criteria & No. of teeth \\
\hline R0 & D0 & No radiolucency & 132 \\
\hline R1 & D1 & Zone of increased radiolucency, confined to outer half of enamel & 17 \\
\hline R2 & D2 & $\begin{array}{l}\text { Zone of increased radiolucency involving both inner and outer halves of enamel } \\
\text { layer, including lesions extending up to but not beyond the DEJ }\end{array}$ & 6 \\
\hline R3 & D3 & $\begin{array}{l}\text { Zone of increased radiolucency penetrating the enamel and DEJ and progressing } \\
\text { into the dentin }\end{array}$ & 14 \\
\hline Total & & & 169 \\
\hline
\end{tabular}

Table 7: Correlation between DIAGNOdent and bitewing radiographs

\begin{tabular}{|c|c|c|c|c|c|c|c|}
\hline & & & & Bitew & graph & & Total \\
\hline & & & $R O$ & $R 1$ & $R 2$ & $R 3$ & \\
\hline DIAGNOdent & Sound & Count & 101 & 7 & 1 & 1 & 110 \\
\hline & & $\%$ & $76.5 \%$ & $41.2 \%$ & $16.7 \%$ & & \\
\hline & Enamel caries & $\begin{array}{l}\text { Count } \\
\%\end{array}$ & $\begin{array}{l}23 \\
17.4 \%\end{array}$ & $\begin{array}{l}6 \\
35.3 \%\end{array}$ & $\begin{array}{l}3 \\
50.0 \%\end{array}$ & $\begin{array}{l}2 \\
14.3 \%\end{array}$ & $\begin{array}{l}34 \\
20.1 \%\end{array}$ \\
\hline & $\begin{array}{l}\text { Dentinal } \\
\text { caries }\end{array}$ & $\begin{array}{l}\text { Count } \\
\%\end{array}$ & $\begin{array}{l}8 \\
6.1 \%\end{array}$ & $\begin{array}{l}4 \\
23.5 \%\end{array}$ & $\begin{array}{l}2 \\
33.3 \%\end{array}$ & $\begin{array}{l}11 \\
78.6 \%\end{array}$ & $\begin{array}{l}25 \\
14.8 \%\end{array}$ \\
\hline Total & & $\begin{array}{l}\text { Count } \\
\%\end{array}$ & $\begin{array}{l}132 \\
100 \%\end{array}$ & $\begin{array}{l}17 \\
100 \%\end{array}$ & $\begin{array}{l}6 \\
100 \%\end{array}$ & $\begin{array}{l}14 \\
100 \%\end{array}$ & $\begin{array}{l}169 \\
100 \%\end{array}$ \\
\hline
\end{tabular}

$\chi^{2}=66.4 ; p<0.001 ;$ VHS: very high significant

and 14 surfaces showed radiolucency extending beyond the Dentinoenamel junction. Table 6 illustrates the radiographic interpretation based on the level of caries.

The statistical analysis correlating the interpretations obtained from DIAGNOdent and bitewing radiograph has been elaborated in Table 7 .

Of the 110 teeth surfaces $(65.1 \%)$ scored as sound (D0) on the DIAGNOdent as against 101 surfaces $(76.5 \%)$ were radiographically sound. Seven teeth surfaces $(41.2 \%)$ recorded as sound by DIAGNOdent showed caries confining to the outer half of the enamel and one tooth surface $(16.7 \%)$ showed caries involving both the inner and outer halves of the enamel, indicating enamel caries radiographically. One tooth surface $(7.1 \%)$ recorded as sound by the DIAGNOdent showed radiolucency extending beyond the dentinoenamel junction, indicating dentinal caries. The sensitivity of the DIAGNOdent technique at the D0 threshold was found to be $76.52 \%$ and the specificity was $75.68 \%$.

Of the 34 teeth surfaces $(20.1 \%)$ scored as enamel caries (D1, D2) by the DIAGNOdent, nine teeth surfaces were found to have radiolucencies within the crown as seen on bitewing radiograph, i.e. six teeth surfaces $(35.3 \%)$ showed radiolucency in the outer half of the enamel, three teeth surfaces $(50.0 \%)$ showed radiolucency in both the outer and inner halves of the enamel. Twentythree teeth surfaces (17.4\%) showed no radiolucency on bitewing radiograph and 2 teeth surfaces $(14.3 \%)$ showed radiolucency extending beyond the dentinoenamel junction suggestive of dentinal caries. The sensitivity of the DIAGNOdent technique to bitewing radiography in diagnosing enamel caries was $39.12 \%$ and the sensitivity was $84.08 \%$.
Of the 25 teeth surfaces $(14.8 \%)$ scored as dentinal caries (D3) by the DIAGNOdent, 11 teeth surfaces (78.6\%) were found to have radiolucencies extending beyond the dentinoenamel junction as seen on bitewing radiographs. Eight teeth surfaces $(6.1 \%)$ showed no radiolucency in radiograph, four teeth surfaces $(23.5 \%)$ showed radiolucency confined to the outer half of the enamel and two teeth surfaces $(33.3 \%)$ showed radiolucency involving both the inner and the outer halves of the enamel. The sensitivity of the DIAGNOdent technique to bitewing radiography in diagnosing dentinal caries was $78.57 \%$ and the specificity was found to be $90.97 \%$.

The Chi-square test showed a strong association between the DIAGNOdent and the bitewing radiography $(\mathrm{p}<0.001)$.

\section{DISCUSSION}

Considering the general decrease in the prevalence of dental caries throughout the world, the employment of diagnostic thresholds that permit the early detection of pathological alteration in dental mineralized tissue has become desirable. ${ }^{20}$ More sensitive diagnostic methods and criteria, including the recording of non-cavitated lesions are necessary. ${ }^{21,22}$ If an initial lesion is detected before the cavitation stage, it can be arrested easily ${ }^{23}$ and probably will prevent future invasive treatment and more serious damage of the dental tissues. ${ }^{23-26}$ Based on such criteria, some authors have defended the investigation of methods for early detection of caries..$^{20,25}$

Concerning the DIAGNOdent, studies have demonstrated that the device is able to detect early caries lesions. ${ }^{27-29}$ An in vitro study showed better results regarding the performance of the DIAGNOdent in detecting 
occlusal caries lesions in advanced enamel caries lesions (D2). ${ }^{28}$ Another in vitro study comparing DIAGNOdent and bitewing radiography in detection of proximal caries in primary teeth demonstrated that the reliability of DIAGNOdent was very high and its diagnostic validity was higher than that of bitewing radiography. ${ }^{10}$ A systematic review reported that there is a lack of evidence related to caries detection in primary teeth. ${ }^{30}$

In the present study, comparisons among DIAGNOdent and bitewing radiography in detection of proximal caries in primary teeth in vivo was carried out, and it was observed that the DIAGNOdent presented better performance when used at the D3 threshold (78.6\%). As the DIAGNOdent device measures the fluorescence from the organic contents of the carious lesions, the device is expected to perform better at dentin threshold than at the enamel threshold. ${ }^{20,28}$

Following the detection of caries at the D3 threshold, the sensitivity of the DIAGNOdent was better at the D0 threshold $(76.52 \%)$. This finding is in agreement with other studies ${ }^{27,31-33}$ conducted for the detection of caries on occlusal surface, which reported a substantial sensitivity using the DIAGNOdent. The advantage of detecting demineralization at this stage allows the early intervention for caries reversal.

At the enamel threshold (D1 and D2), the sensitivity was found to be $39.12 \%$. Within the enamel caries (D1 and D2), detection at the D2 threshold (35.3\%) was better than detection of caries confined to the outer half of the enamel (D1) (50\%).

The overall result shows that the DIAGNOdent can be used as an alternative diagnostic method in detection of proximal caries in primary teeth with the added advantage that there is no exposure to harmful radiation and allowing continuous monitoring of lesions at regular intervals.

When seen at the each caries level, the DIAGNOdent is more accurate at the D0 and D3 threshold.

\section{CONCLUSION}

The DIAGNOdent can be used as an alternative method for detection of proximal caries in children.

The DIAGNOdent device performs better at the dentin (D3) threshold followed by D0 threshold. However, the device does not show good performance in detecting enamel caries (D1 and D2), particularly the initial enamel caries lesions in the proximal surface of primary teeth.

\section{REFERENCES}

1. Mortimer KV. The relationship of deciduous enamel structure to dental disease. Caries Res 1970;4(3):206-223.
2. Wilson PR, Beynon AD. Mineralisation differences between human deciduous and permanent enamel measured by quantitative microradiography. Archs Oral Biol 1989;34(2):85-88.

3. Murray JJ, Majid ZA. The prevalence and progression of approximal caries in the deciduous dentition in British children. Br Dent J 1978;145(6):161-164.

4. Fernandes CA, Tovo MF, Kramer PF, Feldens EG, Ferreira SH, Finkler M. An in vitro study of the correlation between clinical and radiographic examinations of proximal carious lesions in primary molars. J Clin Pediatr Dent 2003;27(2):143-148.

5. Machiulskiene V, Nayvad B, Baelum V. A comparison of clinical and radiographic caries diagnosis in posterior teeth of 12-year-old Lithuanian children. Caries Res 1999;33(5): 340-348.

6. Stecksen-Blicks C, Wahlin YB. Diagnosis of approximal caries in pre-school children. Swed Dent J 1983;7(5):179-184.

7. Pitts NB. Review article. The use of bitewing radiographs in the management of dental caries: scientific and practical considerations. Dentomaxillofac Radiol 1996;25(1):5-16.

8. Murray JJ, Majid ZA. The prevalence and progression of approximal caries in deciduous dentition in British children. $\mathrm{Br}$ Dent J 1978;145(6):161-164.

9. Russel M, Pitts NB. Radiovisiographic diagnosis of dental caries: initial comparison of basic model videoprints with bitewing radiography. Caries Res 1993;27(1):67-70.

10. Virajsilp V, Thearmontree A, Paiboonwarachat D, Aryatawong S. Comparison of proximal caries detection in primary teeth between laser fluorescence and bitewing radiography. Pediatr Dent 2005;27(6):493-499.

11. Hibst R, Paulus R. Caries detection by red excited fluorescence: investigations on fluorophores. Caries Res 1999;33(4):295.

12. Yang J, Dutra V. Utility of radiology, laser fluorescence and transillumination. Dent Clin N Am 2005;49(4):739-752.

13. Shi XQ, Welander U, Angmar-Mansson B. Occlusal caries detection with KaVo DIAGNOdent and radiography: an in vitro comparison. Caries Res 2000;34(2):151-158.

14. Attrill DC, Ashley PF. Occlusal caries detection in primary teeth: a comparison of DIAGNOdent with conventional methods. Br Dent J 2001;190(8):440-443.

15. Franscesut $P$, Lussi A. Correlation between fissure discoloration, DIAGNOdent measurements and caries depth: an in vitro study. Pediatr Dent 2003;25(6):559-564.

16. Shi XQ, Tranaeus S, Angmar Mansson B. Comparison of QLF and DIAGNOdent for quantification of smooth surface caries. Caries Res 2001;35(1):21-26.

17. Wagner M, Longbottom C, Pitts NB. An in vitro comparison of a laser device with bitewing radiography for approximal caries detection. Caries Res 1999;33(4):298.

18. Forgie AH, Pine CM, Pitts NB. Laser fluorscence detection of approximal caries: initial in vitro results. J Dent Res 1999; 78(5):1044

19. Pitts NB. Systems for grading approximal carious lesions and overlaps diagnosed from bitewing radiographs: proposals for future standardisation. Comm Dent Oral Epidemiol 1984; 12(2):114-122.

20. Braga M, Nicolau J, Rodrigues CR, Imparato JC, Mendes FM. Laser fluorescence device does not perform well in detection of early caries lesions in primary teeth: an in vitro study. Oral Health Prev Dent 2008;6(2):165-169.

21. Pitts NB, Stamm JW. International consensus workshop on caries clinical trials (ICW-CCT) - final consensus statements: 
agreeing where the evidence leads. J Dent Res 2004;83(Spec): C125-C128.

22. Warren JJ, Levy SM, Broffitt B, Kanellis MJ. Longitudinal study of non-cavitated carious lesion progression in the primary dentition. J Public Health Dent 2006;66(2):83-87.

23. Kidd EA. The diagnosis and management of the early carious lesion in permanent teeth. Dent Update 1984;11(2):69-70, 7274, 76-78.

24. Angmar-Mansson BE, al-Khateeb S, Tranaeus S. Caries diagnosis. J Dent Edu 1998;62(10):771-780.

25. Stookey GK, Jackson RD, Ferreira Zandona AG, Analoui M. Dental caries diagnosis. Dent Clin North Am 1999;43(4):665-677.

26. Nyvad B. Diagnosis versus detection of caries. Caries Res 2004; 38(3):192-198.

27. Lussi A, Imwinkelried S, Pitts NB, Longbottom C, Reich E. Performance and reproducibility of a laser fluorescence system for detection of occlusal caries in vitro. Caries Res 1999;33(4): 261-299.
28. Alwas-Danowska HM, Plasschaert AJ, Suliborski S, Verdonschot EH. Reliability and validity issues of laser fluorescence measurements in occlusal caries diagnosis. J Dent 2002 May;30(4):129-134.

29. Morgan M. Dental laser identifies early stages of caries. Dent Today 2000;19(2):30-33.

30. Bader JD, Shugars DA, Bonito AJ. A systematic review of the performance of methods for identifying carious lesions. J Public Health Dent 2002;62(4):201-213.

31. Reich E, Al Marrawi F, Pitts N, Lussi A. Clinical validation of a laser diagnosis system. Caries Res 1998;32(4):298, Abstract\# 89.

32. Longbottom C, Pitts NB, Reich NB, Lussi A. Comparison of visual and electrical method with a new device for occlusal caries detection. Caries Res 1998;32(4):298, Abstract\# 90.

33. Azza A. El- Housseiney, Jamjoum H. Evaluation of visual, explorer and a laser device for detection of early occlusal caries. J Clin Ped Dent 2001;26(1):41-48. 